\title{
Breaking down banners: analytical approaches to determining the materials of painted banners
}

\author{
M. J. Smith", K. Thompson and E. Hermens
}

\begin{abstract}
Background: This paper investigates a range of analytical techniques to yield information about the materials and processes used in making painted banners. A textile conservator, technical art historian and paintings conservator, and materials scientist have joined forces to develop a greater understanding of the potential of analytical findings in the identification of materials.

Results: Visual examination using low level magnification and microscopy proved to be a crucial starting point and for identification of areas for further analysis. High magnification microscopy of cross sections was invaluable to gather information regarding the build-up of the layers, their interaction and condition. Scanning electron microscopy (SEM) of ion-milled samples showed that different areas of the banner had been prepared in different ways. SEM-EDX (scanning electron microscopy energy-dispersive X-ray spectroscopy) confirmed the presence of the main elements of pigments. Raman enabled identification of specific pigments. Raman also provided confirmation of specific materials (such as the paint filler). Fourier transform infrared spectroscopy with attenuated total reflectance (FTIR-ATR) enabled the identification of oil and resin, confirmation of pigments and fibres. Thin layers made sampling and identification challenging. Presence of materials such as silk and lead white dominated some analysis making interpretation of other materials more difficult.

Conclusions: Sample preparation had a significant bearing on the effectiveness of the analysis. lon-milling provided high quality surface on the cross section samples that enabled material interfaces to be clearly seen. The challenges of finding effective wavelengths for analysis of samples using Raman were clearly evident in this study. Microscopy showed fibres blends, easily missed using FTIR, whereas FTIR was particularly effective in the identification of manmade fibres. While portable instrumentation may be useful, for in-depth understanding of the heterogeneous layered materials sample taking still remains crucial. Commercial makers used many typical grounds and pigments but these were used sparingly, in thin layers, in order to produce a flexible object and also perhaps to reduce costs. The textile was however of high quality, in this case silk. Unexpectedly, the preparation layers do not appear to be consistent across the banner; the reasons for this need further investigation.
\end{abstract}

Keywords: Painted textiles, Banners, Conservation, Analytical techniques, Degradation, Microscopy, Spectroscopy

\section{Background}

Banners are iconic objects. Many images have been captured showing them billowing in the wind embellished with bold designs as they were carried on procession.

\footnotetext{
*Correspondence: Margaret.Smith@glasgow.ac.uk

Centre for Textile Conservation and Technical Art History School

of Culture and Creative Arts, University of Glasgow, 8 University Gardens,

Glasgow G12 8QH, UK
}

They were and are still widely used by political groups, trade unions, friendly societies, churches and women's organisations [1]. Early banners were painted by sign writers, coach painters or decorators but during the nineteenth century many were made by commercial companies such as George Tutill and Co. and Toye, Kenning and Spencer. Many different materials (e.g. silk, cotton, linen and man-made fibres) and paints (e.g. oil, watercolour,
Springer Open

(c) 2016 The Author(s). This article is distributed under the terms of the Creative Commons Attribution 4.0 International License (http://creativecommons.org/licenses/by/4.0/), which permits unrestricted use, distribution, and reproduction in any medium, provided you give appropriate credit to the original author(s) and the source, provide a link to the Creative Commons license, and indicate if changes were made. The Creative Commons Public Domain Dedication waiver (http://creativecommons.org/ publicdomain/zero/1.0/) applies to the data made available in this article, unless otherwise stated. 
acrylic) have been used. Banners are painted on one side or on two sides of the same fabric or consist of two painted fabrics sewn together. In most cases the paint does not cover the entire surface of the fabric. As they were designed to be carried they have poles sleeves or hanging tabs along the top and sometimes also on side edges. Despite the uncovering of hundreds of painted banners in many collections in the UK, we still know very little about their materials, construction and factors affecting their degradation. In recent years, textile conservators have been working more closely with scientists to develop a better understanding of the materials that comprise banners and painted textiles in general $[2,3]$.

In this study, the analysis of a typical marching banner is carried out to determine the value of techniques commonly used in the analyses of both paintings and textiles, and their appropriateness for the identification of materials and degradation processes, to inform conservation and collection care as well as add to the historical understanding of these objects. Knowledge gained through the different analytical stages shows the potential of each technique and the difficulties that these techniques present. A 1950s banner from the manufacturer George Tutill \& Co. is used as a case study for this purpose.

The identification of materials is done using widely utilised instrumentation such as microscopy, scanning electron microscope (SEM), Fourier transform infrared spectroscopy (FTIR), Raman etc. In addition to identifying the materials, the challenges associated with these types of objects in terms of sample preparation and subsequent analysis is discussed. Lastly the use of specialised preparation techniques such as ion-milling are reported. The results will enable conservators to see the value of materials analysis to their work. This study of a hierarchy of analytical techniques shows the role of different techniques in developing our understanding of painted textiles.

\section{Experimental \\ Object and reconstructions}

The banner used in this study belongs to the Karen Finch Reference Collection housed at the Centre for Textile Conservation and Technical Art History, University of Glasgow. It is a marching banner, measuring approximately $230 \mathrm{~cm} \times 245 \mathrm{~cm}$ and depicting the Loyal Orange Lodge (Fig. 1), made by the company George Tutill \& Co., and is thought to date from the 1950s [4]. The banner comprises a single layer of dyed orange textile with dyed blue textile borders on three sides. Guide tapes are attached near the bottom of the banner and can be seen in Fig. 1b. It hangs from a wooden pole by textile tabs and is decorated with a blue and orange fringe on the lower edge. The textile components are machine stitched together. The pole has a metal cap on each end with rings which would have been attached to wooden side poles when the banner was carried in a March. The central orange panel is painted on both sides. The paint does not cover the entire surface and there are large unpainted areas. The paint covers the same area on both sides but each side depicts a different design. Four positions were sampled (1-4, Fig. 1) in a number of different ways in order to fully explore the material composition of the banner. For the purposes of this research the location of the samples is referred to from the front of the banner. Samples were taken from areas where there was previous damage and/or sampling had already been carried out. Full sections of ca $1-2 \mathrm{~mm}^{2}$ were taken by cutting
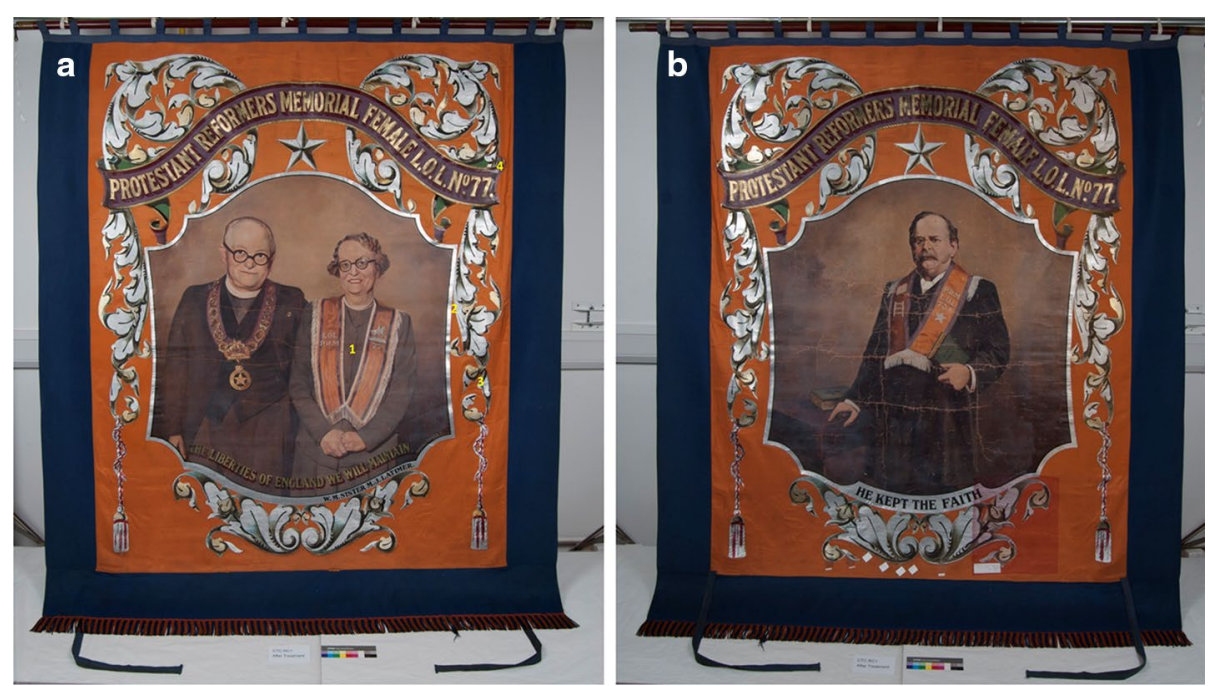

Fig. 1 Banner by George Tutill \& Co. showing the front (a) and the back (b). The figures in yellow on a mark the four sampling positions 
through the banner using a scalpel to obtain a complete cross section for examination. Samples of only the paint layers were also taken from areas where different colours and types of paints (matt, translucent and metallic) were used. It was not possible to take paint samples close to the edges of the banner as could be done with a painting because the silk extends beyond the painted image so such sampling from a banner in good condition could be problematic. The wood and metal were not sampled. Table 1 details the sampling methods and positions.

Reconstructions of silk fabric coated with a preparatory layer of latex rubber or rabbit skin glue followed by a paint layer of zinc white pigment mixed with linseed oil were made in order to determine if the analytical methods used to identify the materials were successfully detecting the materials in each layer. These were created based on a 1861 patent (George Tutill \& Co.) for the preparation of painted banners, as published by Labreuche [5] who reported on the nineteenth century use of latex rubber in the preparation of painted canvases, and on a discussion with banner makers George Tutill Flags (April 2014).

\section{Instrumentation}

\section{Light microscopy}

Low magnification microscopy was carried out using a Zeiss stereo-microscope (Stemi SV 11). Loose fibre samples were studied using a Zeiss Axiolab Pol (polarising microscope).

Embedded cross sections were prepared from samples by mounting them in clear light curing resin (Technovit 2000LC, Kulzar). The resin blocks were prepared in silicone moulds and were cured in a UV curing unit (Technology $\mathrm{Cu}$, Heraeus) for $30 \mathrm{~min}$. The final polish was carried out using 12,000-mesh Micro-Mesh ${ }^{\circledR}$ polishing paper. Although the polishing removed the majority of the resin some remained on the sample due to the nonconformal nature of painted cross-section. In addition it was difficult to polish painted textile to the same level of traditional oil paint cross-section because of the presence of the textile fibres tended to be abraded unevenly. Embedded cross sections were examined under visible and ultraviolet illumination using an Olympus BX41 microscope and Olympus Stream Start 1.8 image analysis software.

\section{Scanning electron microscopy with energy-dispersive X-ray spectroscopy}

Samples of the banner were viewed using an energy-dispersive X-ray (EDX) micro-analysis in conjunction with scanning electron microscopy (SEM-EDX), Camscan DX 4800 scanning electron microscopy and secondary electron, backscatter electron and absorbed current detectors (SEM-BSD, SE and AEI) and a Carl Zeiss EVO MA15 variable pressure W SEM with Oxford Instruments AZtecEnergy EDX system with $80 \mathrm{~mm}$ X-Max SDD detector-secondary and backscattered imaging, EDX elemental mapping and linescans plus CZ STEM detector. The analysis depth is commonly around 1 to $2 \mu \mathrm{m}$ and the lateral dimensions tend to be about $1 \mu \mathrm{m}$. The quantitative results progressively improve as the element becomes heavier. To achieve very smooth surfaces, some samples were ion-milled using a Hitachi IM4000Plus ion polisher. The following instrumental conditions were used: flat milling with sample rotation and periodic beam irradiation interruption, beam-on for 1 rotation $(25 \mathrm{rpm}$, means $2.4 \mathrm{~s}$ ), beam-off for $27.6 \mathrm{~s}(30 \mathrm{~s}$ period) total processing time 99 min (beam-on total $475 \mathrm{~s}$ ), beam energy $4 \mathrm{keV}$, beam current $\sim 135 \mu \mathrm{A}$, and irradiation angle $60^{\circ}$ from vertical and zero excentricity.

\section{Fourier transform infrared spectroscopy with attenuated total reflectance}

Fourier transform infrared spectroscopy with attenuated total reflection (FTIR-ATR) was carried out using Perkin Elmer Spectrum One FTIR Spectrometer with Spectrum software version 5.0.1 and fitted with a Universal ATR Sampling Accessory. The ATR crystal used was a diamond/thallium-bromoiodide (C/KRS-5) with a penetration depth up to $2 \mu \mathrm{m}$ ATR-FTIR is primarily a surface technique and the exposed diameter of the crystal was $1.33 \mathrm{~mm}$ resulting in a sample area of around $1.39 \mathrm{~mm}^{2} .32 \mathrm{scan}$ accumulations were used at a resolution of $4 \mathrm{~cm}^{-1}$.

\section{Raman}

Micro Raman analysis was carried out on two instruments which allowed the use of a total of four excitation wavelengths. The first instrument was a Renishaw inVia Raman Microscope, with Wire 3.4 software. It was calibrated

Table 1 Sample position, area detail and sample type

\begin{tabular}{lll}
\hline Sample position & Sampling positions (detailed Fig. 1a) & Sample type \\
\hline P1 & Above second button from top on ladies jacket & Cross sections and loose threads \\
P2 & Paint from edge where silk is split, above ladies shoulder & Cross section and paint scraping \\
P3 & Silver painted area in line with lady's bottom button & Cross sections \\
P4 & Edge of scroll, wine paint above the full stop after No. 77 & Cross sections and paint scraping \\
\hline
\end{tabular}


using silica at $520 \mathrm{~nm}$. Two excitation wavelengths were used for analysis; a gas laser source at $488 \mathrm{~nm}$ wavelength with a possible maximum power of $10 \mathrm{~mW}$ and a diode laser of $785 \mathrm{~nm}$ wavelength with a maximum power at sample of $200 \mathrm{~mW}$. Full power was never used for either wavelength and was $5 \%$ or less of full power. The $488 \mathrm{~nm}$ excitation wavelength grating had 2400 lines $\mathrm{mm}^{-1}$ and the $785 \mathrm{~nm}$ excitation wavelength has 1200 lines $\mathrm{mm}^{-1}$ both had a $1040 \times 256$ CCD detector. Further work was done on a LabRAM HR system, manufactured by Horiba Jobin-Yvon equipped with a Ventus 532 laser system 100 $\mathrm{mW}$ and a Helium Cadmium IK3201R-F, $20 \mathrm{~mW}, 325 \mathrm{~nm}$, using a $1024 \times 128 \mathrm{CCD}$ detection system. Analysis was carried out on this instrument using excitation wavelengths of $532 \mathrm{~nm}$ and $325 \mathrm{~nm}$, with gratings of 600 and 1200 lines $\mathrm{mm}^{-1}$ respectively. On both instruments the samples were focused using $20 \times$ and $50 \times$ objectives. The spectral resolution ranged from 1 to $4 \mathrm{~cm}^{-1}$ depending on the wavelength employed and the measurements were performed with a slit opening of $65 \mu \mathrm{m}$.

\section{Results}

\section{Visual inspection and low level microscopy}

The banner was examined by eye and with low level magnification. Through this process it was possible to determine a broad categorisation of materials, the banner's construction and painting techniques. Close study of the textile-paint interface indicated evidence of a possible preparatory layer applied directly to the silk (Fig. 2a). Figure $2 \mathrm{~b}$ shows a transparent yellow toned coating/varnish layer over the silver-coloured paint to create a gold colour that appears to overlap onto the silk. These preparatory layers, paint layer and the coating/varnish have considerably stiffened the silk.

The condition of the textile, paint and paint-textile interfaces including presence of soiling, creasing, splits and abrasion were documented based on visual and lowlevel microscopy. The differences in flexibilities between the painted and unpainted areas were evident. Paint deformation resulting from previous storage around the narrow banner pole and areas of paint loss associated with flexing and creasing are evident (Fig. 2c, d). Some of these distortions may be the result of different flexibilities of the materials but also different responses to environmental conditions between the painted and unpainted areas. This damage is typical for banners [6].

Under low level magnification micro-cracking of the paint surface and paint losses (Fig. 2c, d) were visible, particularly on the areas with several layers of paint.

\section{Light microscopy}

Due to previous substantial damage it was possible to be able to take cross-sections that comprise the whole layer build-up of the preparatory, paint and varnish layers on both sides of the silk support. Fibre identification, longitudinal and cross section, was carried out on the banner and the fringe. The banner was identified as silk and the fringe was a mixture of cotton and a man-made fibre. The man-made fibre was confirmed by FTIR as viscose rayon. Polarised light microscopy from P1 (Fig. 3) shows a layer build up starting with a white preparation/priming layer of ca. $50 \mu \mathrm{m}$ that seems to have impregnated the silk support on both sides. This is followed by one thin further paint layer on each side of the banner (ca. $10 \mu \mathrm{m})$. A similar white ground has been found on many mid nineteenth to early twentieth century processional painted banners, most of them on a silk support [2, 7]. In P4 (Fig. 4) there is a silver coloured paint layer which was identified as aluminium (see SEM-EDX results) (ca. $10 \mu \mathrm{m}$ ), which in some places of the cross-section is covered by a transparent yellow layer, discernible in UV, applied to make the silver coloured paint appear golden. Figure 5 shows a loose sample again of the white ground layer with a red paint layer which appears glossy due to a coating of a resin based varnish (see FTIR results).

Protein staining was carried out on embedded cross sections following a method detailed by Schäfer [8]. The metal chelate stain, SYPRO ${ }^{\circledR}$ Ruby was used as it is readily reversible, does not modify the protein and is compatible with mass spectrometry. Figure 6 shows an embedded sample from P3. It can be seen that the silk, a large part of the sample, stains as it is a protein. The method was developed to identify and localise the presence of protein in historical paint cross sections. Here it also functions to indicate the protein fibre component, silk. There is also evidence for a protein type material within the areas where the metallic paint has been used. However, it is not possible to identify from this test alone which type of protein it is. An analysis technique such as gas chromatography with mass spectrometry would be required to do this [9].

\section{SEM and EDX}

Figure 7 shows a scanning electron microscopy (SEM) image of a loose sample taken from P1. A cross section sample taken from P1 was examined on both sides using SEM-EDX. Analysis of the back of the banner detected lead and traces of aluminium, silicon, potassium, sodium and calcium. The lead is likely to be attributed to lead white commonly used as a ground layer in banners made by Tutill [2]. Analysis of the metallic paint (P2) showed the presence of aluminium which is frequently used in metallic paints to give the appearance of silver.

Ion-milling to produce high quality smooth samples has been used in materials analyses for a considerable time [10] and was investigated here. Ion-milling involves hitting the sample surface with accelerated submicron ion 



Fig. 2 a Silver and black paint on orange silk with evidence of a possible preparation layer extending beyond the silver darkening the silk. $\mathbf{b}$ A clear coating/varnish layer on the silver paint to create a gold colour which extends onto the silk. $\mathbf{c}$ Build of several layers of paint has been applied to create detailing. Cracking of paint surface is evident. $\mathbf{d}$ Loss of top layer of paint exposing light coloured ground layer and characteristic splits in the silk between painted areas

particles while it is mounted on a rotating table inside a vacuum chamber. Its first reported use in a cultural heritage application was published in 2006 by Boon and Asahina [11]. Subsequently work by Prati et el. [12, 13] has shown the advantages of ion-milling embedded paint samples. Figure $8 \mathrm{a}$, b shows an embedded sample before and after ion-milling, demonstrating the high structural definition of the different materials and distinctive layers not routinely seen with traditional polishing techniques. Figure 9 shows ion-milled samples ( $\mathrm{a}$ and $\mathrm{b}$ ) taken from $\mathrm{P} 1$ and $\mathrm{P} 4$ respectively indicate that different preparation techniques have been used on the same banner i.e. Fig. 9a shows the inorganic materials from the ground layer spread though out the silk fabric while Fig. 9b shows a preparatory organic layer on the silk fabric preventing the ground paint from having contact with the silk. This use of different preparation techniques on different parts of the same banner has not been reported before.

\section{FTIR-ATR}

All the FTIR analysis was done using the external ATR arm and thus is considered macro (bulk) analysis. A large range of materials was identified.
Samples from the fabric and fringe were analysed with standards from a fabric supplier (Whaleys, Bradford, UK) used as reference material. FTIR-ATR confirmed the use of silk for the fabric and a mixture of viscose rayon and cotton for the fringe. Figure 10 shows the spectrum obtained from side 1 of a sample taken from P4 compared with a spectrum of new silk. The amide I and amide II bands at 1620 and $1514 \mathrm{~cm}^{-1}$ respectively, are associated with the fibroin component of the silk. Other fibroin related bands at 1442 and $1164 \mathrm{~cm}^{-1}$ arise from the vibrations of the side chains of alanine and tyrosine in the silk [14]. FTIR gave a clear molecule signature for silk.

Figure 11 shows the spectra obtained from the two thread types taken from the fringe on the bottom of the banner. One thread type has been identified as cotton and the other as viscose rayon. The FTIR spectra of these materials are very similar. However, a peak around $1100 \mathrm{~cm}^{-1}$ associated with the glucose ring is present in cotton but missing in the viscose rayon.

Figure 12 shows the spectrum of sample P1 compared with spectra of linseed oil (aged), calcium carbonate, lead white and silk. It is not possible to identify 

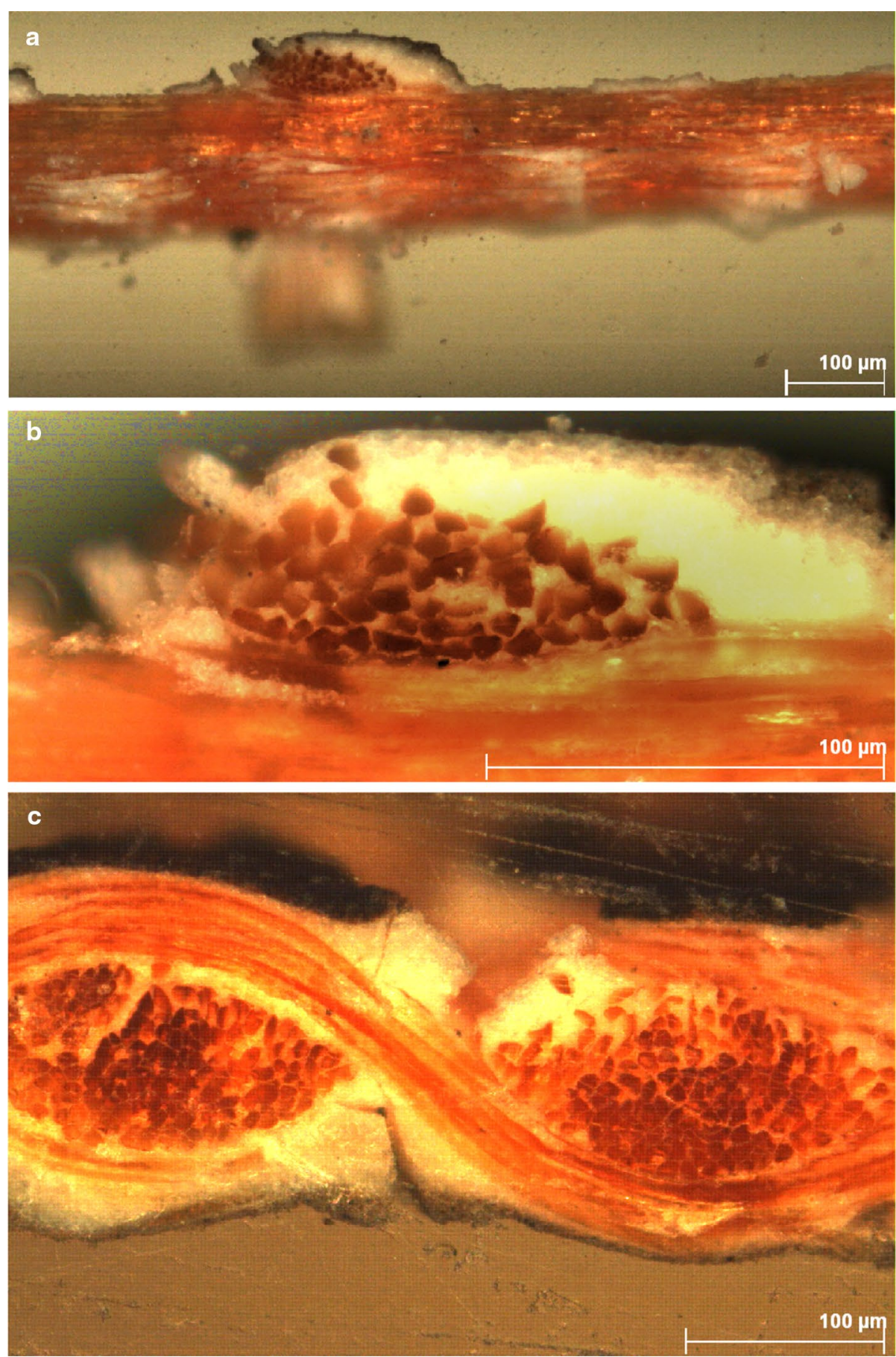

Fig. 3 Polarized light microscopy of the cross sections from P1 of a sample $(\mathbf{a}, \mathbf{b})$ and another sample. cThe silk, base layer, ground layer and the paint layer

any of the materials with $100 \%$ certainty as often broad bands mask the presence of narrow bands that would appear within their area. However, bands at wavenumbers specific to linseed oil, silk, calcium carbonate, and lead white were detected. Linseed oil has very strong $\mathrm{CH}_{2}$ asymmetric stretching at $2920 \mathrm{~cm}^{-1}$ and strong $\mathrm{CH}_{2}$ stretching $2850 \mathrm{~cm}^{-1}$. The $\mathrm{C}=\mathrm{O}$ stretching is seen around $1740 \mathrm{~cm}^{-1}$ and $\mathrm{C}-\mathrm{O}$ ester stretching at around $1160 \mathrm{~cm}^{-1}$. The broadening of the $\mathrm{C}=\mathrm{O}$ peak at $1740 \mathrm{~cm}^{-1}$ is indicative of the hydrolytic degradation 

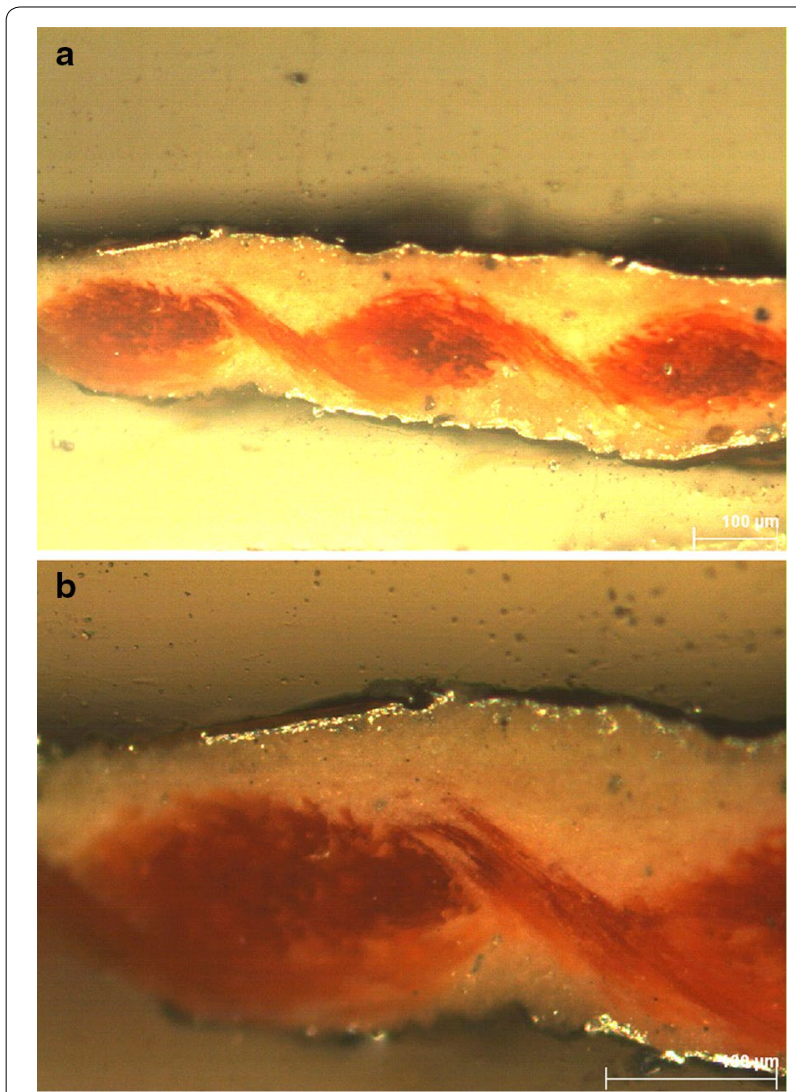

Fig. 4 Polarized light microscopy of the cross section from P3 showing the metallic paint layer at different levels of magnification, $\mathbf{a} \times 100 \mu \mathrm{m}$ and $\mathbf{b} \times 100 \mu \mathrm{m}$

of triglycerides which leads to the formation of the free fatty acids which is seen here [15]. Additionally the peak at around $1706 \mathrm{~cm}^{-1}$ may be associated with fatty acids formed by hydrolysis of glycerol esters [16]. Lead white has a strong band at around $1370 \mathrm{~cm}^{-1}$ assigned to the $\mathrm{CO}_{3}^{-2}$ and a band around $680 \mathrm{~cm}^{-1}$ both seen on the banner spectrum. Calcium carbonate also exhibits a broad band around $1392 \mathrm{~cm}^{-1}$ but additionally at $872 \mathrm{~cm}^{-1}$ which is seen here. Silk is also seen at $1618 \mathrm{~cm}^{-1}$, $1531 \mathrm{~cm}^{-1}$ associated with the amides I and II.

The banner exhibited areas of an opalescent bloom previously reported to be present on marching banners and which could be attributed to the formation of metal soaps $[17,18]$. The simultaneous presence of free fatty acids in the binders and metals from pigments make the formation of soaps predictable [19]. However micro-pitting of the paint surface or mould are also known to cause bloom. The spectrum of a sample from P4 showed two strong sharp bands between 1500 and $1600 \mathrm{~cm}^{-1}$ one at around 1586 and another at $1538 \mathrm{~cm}^{-1}$ as a result of COO- asymmetric stretching associated with calcium soaps $[20,21]$. The $\mathrm{CO}_{3}^{-2}$ of $\mathrm{CaCO}_{3}$ creates a broad
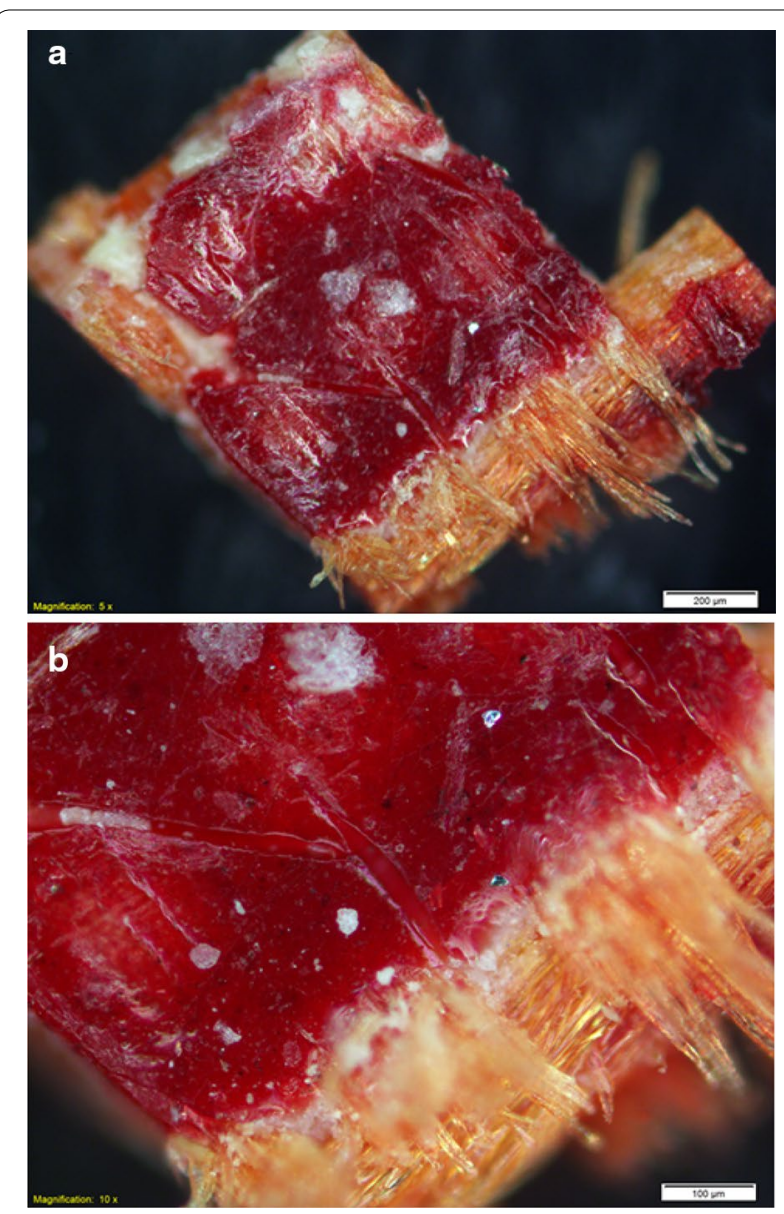

Fig. 5 Light microscopy images of a sample from P4 showing the red translucent glaze, $\mathbf{a} \times 50$ and $\mathbf{b} \times 100$

band at around $1400 \mathrm{~cm}^{-1}$ which masked the symmetric bands of the calcium soaps. However by performing first derivative calculations, the overlapping peaks could be seen at around 1472, 1433 and $1420 \mathrm{~cm}^{-1}$ which are all absorbance bands present in calcium soaps. The formation of the soaps is also confirmed by the reduced presence of the $\mathrm{C}=\mathrm{O}$ ester and acid stretching at 1700 $1750 \mathrm{~cm}^{-1}$ associated with the linseed oil components. Despite the presence of lead white detected on most of the samples from the banner the formation of lead soaps, on the samples analysed, was not detected as the doublets associated with lead soaps occur at lower frequencies $1540-1500 \mathrm{~cm}^{-1}$ [22] and these were not seen on the spectrum. However, this may be due to the use of macro FTIR and it may be that the use of micro FTIR may have found these soaps to be present. Therefore it cannot be deduced from these results that they were not present.

A sample from the red translucent paint at P4 (see Fig. 5 for light microscopy image) appeared to contain a resinous material and produced a spectrum indicating 

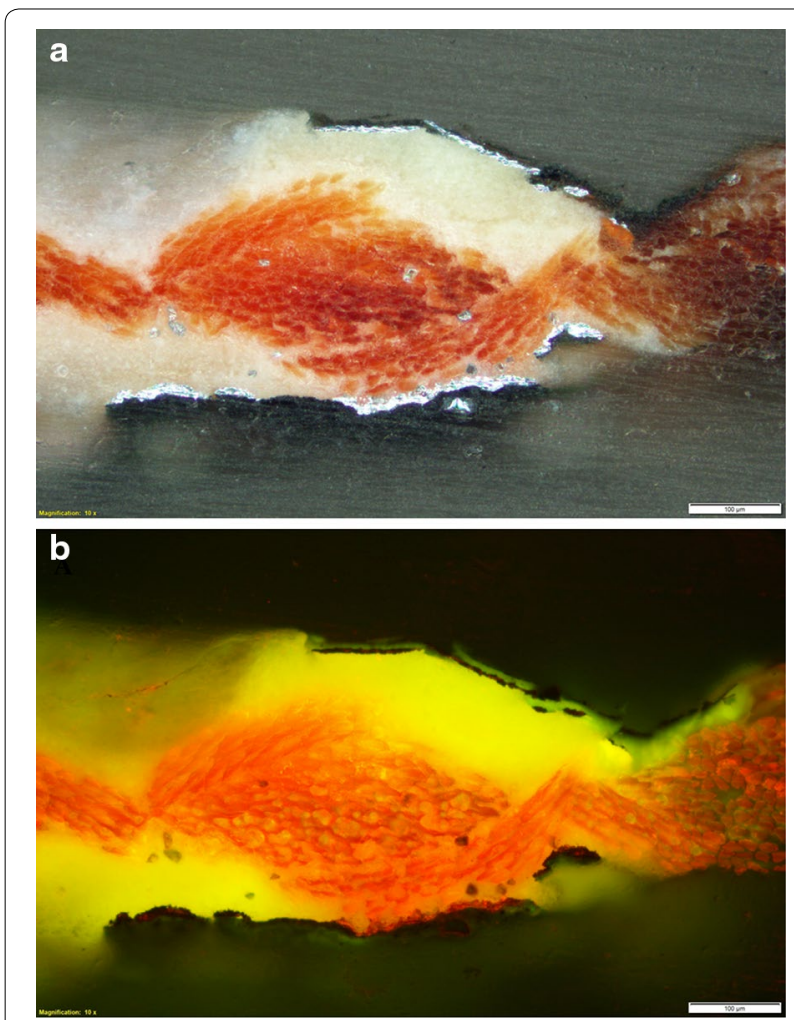

Fig. 6 a The sample without staining, $\times 100$. b Sample area with protein stain $\times 100$. Note staining evident on silk and on silver paint

that it was possibly shellac, as a broad doublet type $\mathrm{C}=\mathrm{O}$ band around the lower regions of $1700 \mathrm{~cm}^{-1}$ was observed as well as a band at $1636 \mathrm{~cm}^{-1}$ associated with the $\mathrm{C}=\mathrm{C}$ bonding. Identifying differences in spectra between aged drying oil and resin proved difficult as the $\mathrm{C}=\mathrm{O}$ band broadens to lower frequencies in oil due to ageing. However, the vinyl band at $1636 \mathrm{~cm}^{-1}$ present in shellac but not oil and a strong band at $1160 \mathrm{~cm}^{-1}$ in oils which is weaker in shellac can help differentiate. Additionally the $\mathrm{C}=\mathrm{O}$ doublet seen in shellac resin is not seen in drying oil. Figure 13 shows the banner spectrum compared with shellac (supplied A.F.Suter, London). For confirmation of shellac the detection of erythrolaccin (a yellow dye present in shellac) could be achieved using high performance liquid chromatography.

Attempts to identify the possible unknown preparatory layer which was visible by eye and on the ion milled samples (Fig. 9) were explored. Spectra were compared with a spectrum of latex rubber known to have been used on painted banners [7] and rabbit skin glue commonly used on paintings. Neither of these was detected on this banner using FTIR. The FTIR analysis of the reconstructions showed that some combinations of materials are very difficult to detect. The spectrum of the combination of silk fabric coated with a $20 \%$ (aq) latex rubber solution is shown in Fig. 14a. Here it is possible to see the absorbance bands associated with silk but the latex rubber bands are not easily identified despite their occurrence at different areas on the spectrum. Figure $14 \mathrm{~b}$ shows the spectrum of the silk with $10 \%(\mathrm{aq})$ rabbit skin glue. As would be expected, as both are proteins, it is not possible to identify the presence or absence of rabbit skin glue. This problem with using this type of analytical methodology to analyse multi-layered samples has been noted [23]. Often characteristic absorptions of some materials are masked by stronger bands of others. Therefore we cannot conclude from the FTIR results that a preparatory layer is not present only that it cannot be detected in this case.

Fourier transform infrared spectroscopy microscopy was not carried out here. This technique is able to achieve high spatial resolution and gains in sensitivity in detecting trace materials and it may have yielded information on the specific location of materials in the unembedded samples. However, the problems associated with bands from resin interference in embedded samples often prevents identification of oils resins etc. as the absorbance bands associated with these appear in the same parts of the spectrum. Much research is being done to prepare successful cross sections in materials which have less detrimental effects on the analysis [24, 25].

\section{Raman}

Work concentrated on optimising micro-Raman analysis conditions, by using different excitation wavelengths, exposure times and power settings to detect the differing materials within the samples. Additionally care was taken to choose settings which did not damage the sample through overheating. Analysis at $488 \mathrm{~nm}$ yielded poor results for the embedded samples as all spectra were badly affected by fluorescence. A loose sample from P1 did produce a spectrum but required a high power setting of $50 \%$, which could potentially damage the sample. Using lower power settings yielded no information. In contrast using an excitation wavelength of $785 \mathrm{~nm}$, exposure time of $10 \mathrm{~s}$ and power setting of $0.1 \%$ on an embedded sample from P1 produced a good spectrum from the dark area (top paint layer). The peak at $544 \mathrm{~cm}^{-1}$ has been identified as red lead by comparison to a minimum standard, a red lead mineral (supplied by National Museums Scotland Collection), Fig. 15. The peak at $1086 \mathrm{~cm}^{-1}$ visible on the spectrum of the embedded sample is indicative of calcite (calcium carbonate) which is often used as pigment filler [26, 27].

Using $785 \mathrm{~nm}$ and $0.1 \%$ power produced good spectra for lead white in both embedded and loose samples. Figure 16a, b show spectra of lead white. Figure 16a shows the spectra as they were collected and Fig. 16b shows them with baseline smoothing and the wavenumber range reduced. The detection of lead white occurs 



Fig. 7 SEM from P1. a Front showing the cracking of the paint. b Detail of the cracking. c Back showing less paint coverage. d Detail of the paint in patches on the silk


Fig. 8 SEM of an ion-milled embedded cross section samples from P1. a Before ion-milling. b After ion-milling 

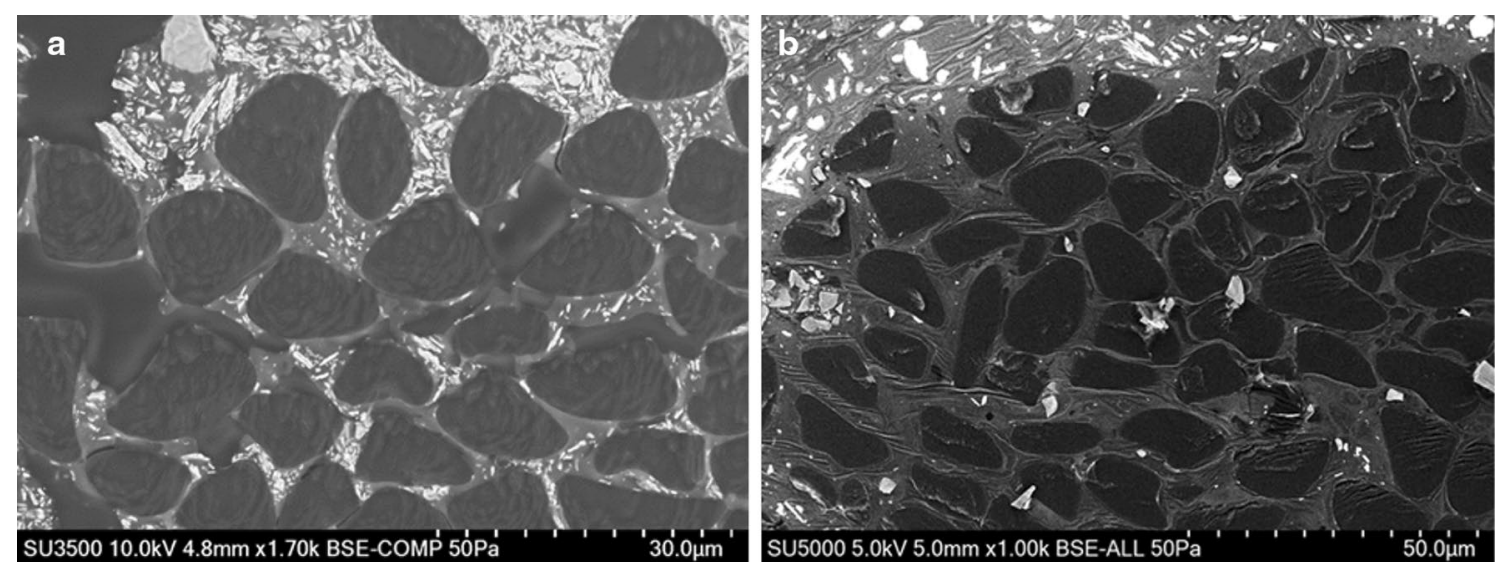

Fig. 9 lon-milled samples. a P1 ground layer within silk. b P5 preparatory layer preventing ground layer seeping into the silk

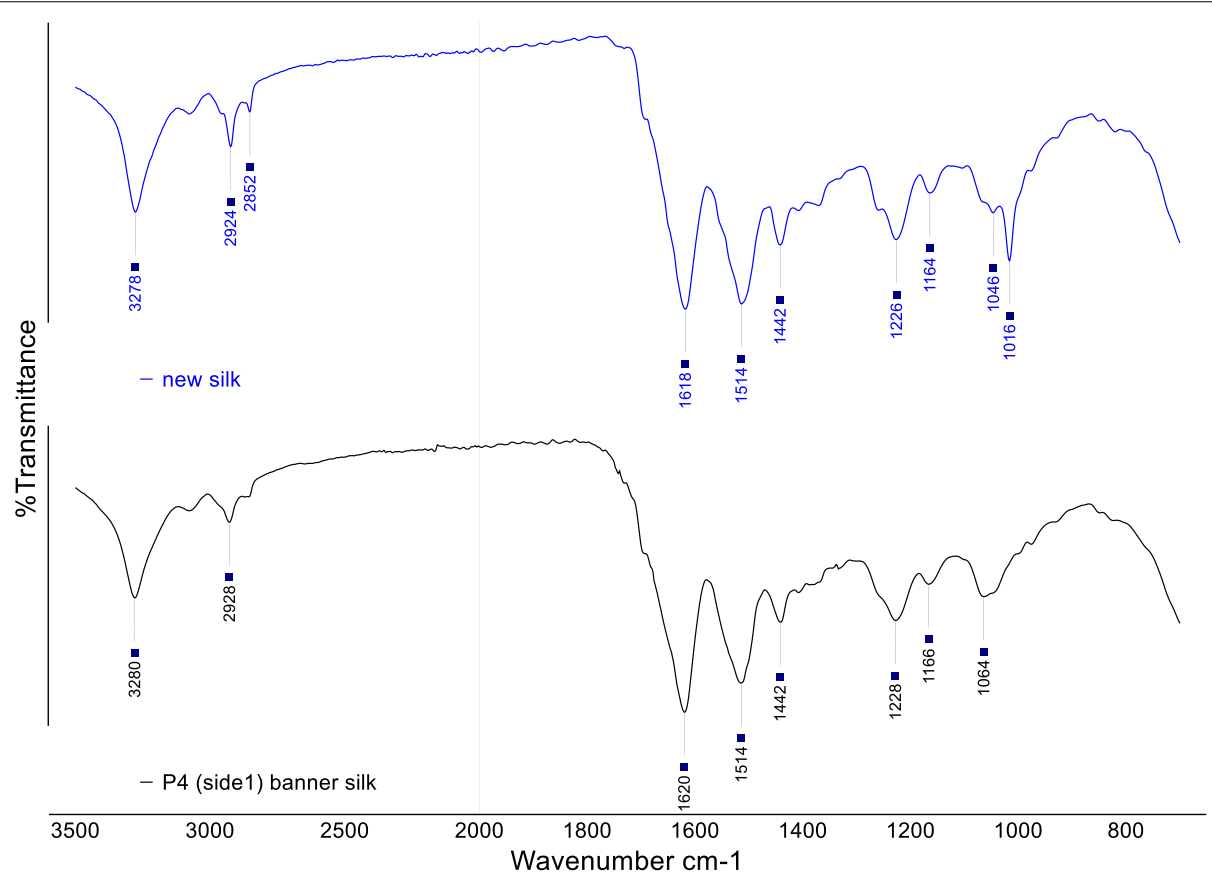

Fig. 10 FTIR-ATR spectrum of banner silk (P4 side 1) compared to a spectrum of a new silk sample

at around $1050 \mathrm{~cm}^{-1}$ (when compared to the spectrum produced from the lead white mineral cerussite, RRUFF database) in the samples P1 embedded, P1 loose sample and P3 loose sample. Additionally a good spectrum for the identification of lead white was achieved using the Renishaw system at $325 \mathrm{~nm}$ for a loose sample from P1.

The use of Raman to identify the silk in embedded and loose cross sections proved to be difficult. Figure 17 shows the spectrum of embedded silk at the $785 \mathrm{~nm}$ excitation wavelength showing it was difficult to obtain a good quality spectrum for silk for an embedded cross section due to the extent of fluorescence from the resin block as well as the fibre. However, with baseline correction and truncating of the sample spectrum two peaks were identifiable when compared to the spectrum obtained from a loose silk sample (new), one being associated with silk $1665 \mathrm{~cm}^{-1}$ but the other $\left(1588 \mathrm{~cm}^{-1}\right)$ most likely due to the embedding resin (see Fig. 17). This problem was noted by Macdonald et al. [2] when analysing cross sections of banners with Raman. 

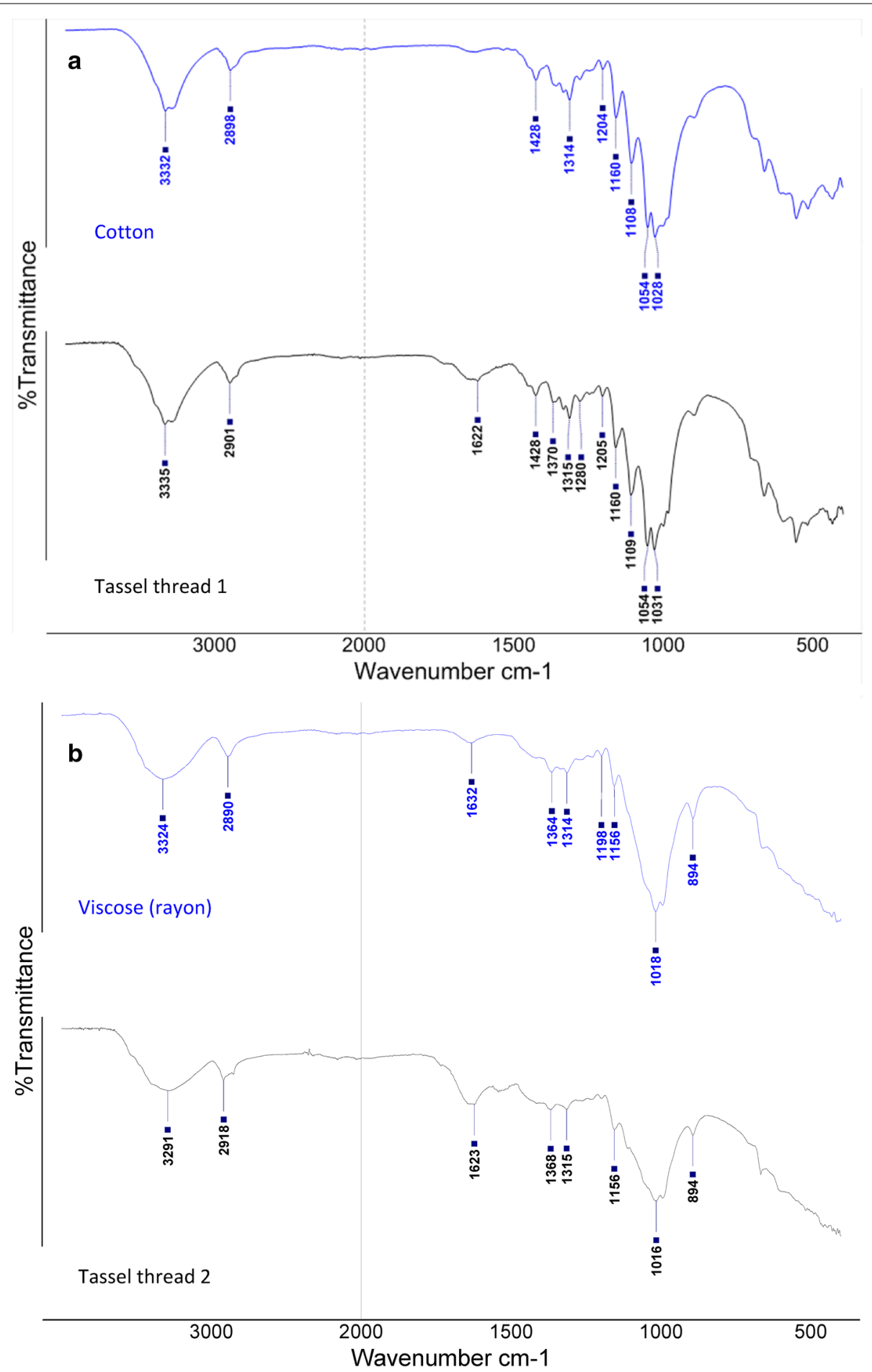

Fig. 11 FTIR-ATR spectra from the fringe are confirmed as a combination of both cotton (a) and viscose (b) by comparison to a spectrum from a new cotton and viscose rayon sample

Problems with intense fluorescence signals from organic materials and dyed fabrics have been documented [28, 29]. These signals often mask the signals for the lesser reacting molecules. The use of confocal Raman microscopy has been reported as a way to prevent this [29] and Lorenzetti et al. [30] reported on its usefulness 


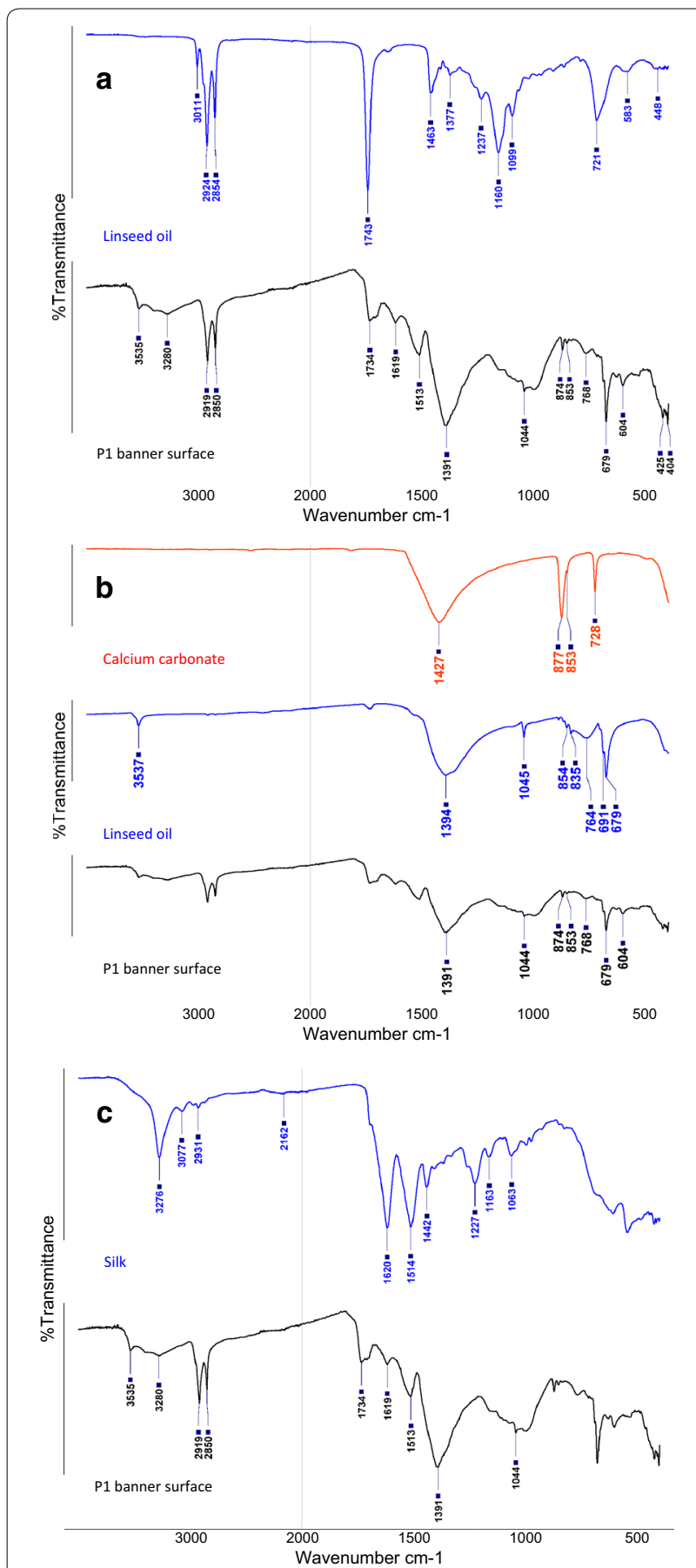

Fig. 12 FTIR-ATR spectrum of a sample from the banner surface P1 compared with spectra of a linseed oil, $\mathbf{b}$ calcium carbonate and lead white and $\mathbf{c}$ new silk

to determine the dyes on historic dyed cotton yarns by using a confocal condition 2-3 $\mu \mathrm{m}$ lower than the fibre surface. However Macdonald et al. [31] reported that the results often included output from both above and below the point of focus and so these contributed to the Raman response albeit to varying degrees. Thus the use of confocal microscopy may not be ideal as it is not always certain which area in the sample yields the results. When using Raman to analyse samples from painted textiles the presence of the textile such as silk, as well as the typical organic oils and resins associated with pigments, mean that fluorescence signals will be strong from such samples so care has to be taken when processing these results.

In summary a total of four different wavelengths were used in the analysis, ranging from $325 \mathrm{~nm}$ in the ultraviolet range, 488 and $523 \mathrm{~nm}$ in the visible range and $785 \mathrm{~nm}$ in the infrared region. The analysis of cross sections, either loose or embedded, was most successful using an excitation wavelength of $785 \mathrm{~nm}$. Relatively strong signals were obtained using short scan times typically of around $10 \mathrm{~s}$. Using the excitation wavelength $325 \mathrm{~nm}$ reduced fluorescence but failed to detect pigments, excepting lead white, or silk with any degree of certainty. Similarly Burrafato et al. [28] compared the use of three excitation wavelengths 531.5, 632.8 and $780 \mathrm{~nm}$ for the identification of pigments both dry and in egg tempera, casein tempera, oil and fresco. They reported that the presence of other materials often made detection difficult or impossible e.g. cinnabar in oil could only be detected using $780 \mathrm{~nm}$. The use of Fourier Transform (FT) Raman at $1064 \mathrm{~nm}$ has been reported to be useful for the determination of organic materials such as dyes as it does not suffer from fluorescence interference. The signal from the sample is weakened at this wavelength [32] however the use of a sensitive single element such as indium gallium arsenide or liquid nitrogen-cooled germanium plus an interferometer converting the Raman signal greatly improves the output. Perhaps this wavelength's use, due to reduced fluorescence, would have helped in identification of some materials here.

\section{Discussion}

From the samples analysed a range of pigments, lead white, calcium carbonate and red lead were identified. EDX alone detected the presence of aluminium which was a component of the silver coloured paint used. The presence of oil was detected as a component within the pigments with no indication that the recently developed acrylics had been used. Shellac was most probably used to create a glazed appearance on the banner and also used to coat the wooden support pole.

George Tutill and Co. manufacturing banners in 1837, using oil paints for its designs and traditional pigments. By the 1950s however, the company would have had availability of a wide range of paints with a variety of binding media and modern, synthetic pigments, as well as metallic, such as the aluminium paint, and 




Fig. 13 FTIR-ATR spectrum of a red translucent sample from the banner surface P4 compared with a spectrum of dewaxed bleached shellac (A.F. Suter, London)

enamel paints, much in accordance with what artists were using and experimenting with [33]. However, traditional oils were still used in the banner despite the availability of more modern paints. Table 2 summaries the materials identified and the techniques used.

Visual examination using low level magnification and microscopy proved to be a crucial starting point to understand the nature of the materials being studied and to identify areas for further analysis. It is clear that important information can be gleaned from visual observation and low level microscopy.

A cross section through all layers was invaluable to gather significant information regarding the build-up of the layers, their interaction and condition. Sampling paint alone was problematic as the paint layers were very thin and crumbled easily and it proved difficult to sample the layer closest to the silk. Additionally the flexibility of the silk also created more movement than sampling from a taut canvas. Sample preparation had a significant bearing on the effectiveness of the analysis. Ion-milling provided high quality samples for SEM that enabled the material interfaces to be clearly seen. Of particular interest was the presence of an organic preparatory layer on some areas of the silk which may explain the darkening on the silk around the edges of the paint. This was not visible on samples which were prepared by polishing with cloths.
Scanning electron microscopy energy-dispersive X-ray spectroscopy confirmed the presence of main elements whereas Raman enables identification of specific compounds. The challenges of finding effective wavelengths for analysis of samples using Raman were clearly evident in this study. Previous work using Raman by Macdonald et al. [2] concentrated on identification of paint pigments used in painted banners as the authors stated that this would assist conservators to understand degradation as well as helping with dating and attributions. This is certainly true but to determine where degradation has occurred other materials (such as base and preparatory layers, grounds and varnishes) used in painted banners must also be identified. Raman analysis also provided confirmation of specific materials (such as paint fillers) which is useful in building a better understanding of the banners.

Fourier transform infrared spectroscopy with attenuated total reflectance enabled the identification of oil associated with the pigment, shellac used for glazing and coating the support pole, further confirmation of pigments and man-made fibres. The use of microscopy (longitudinal and cross section) was very effective and clearly showed mixed fibres. FTIR was particularly valuable in identifying manmade fibres as they can be difficult to determine using microscopy alone. This highlights the 


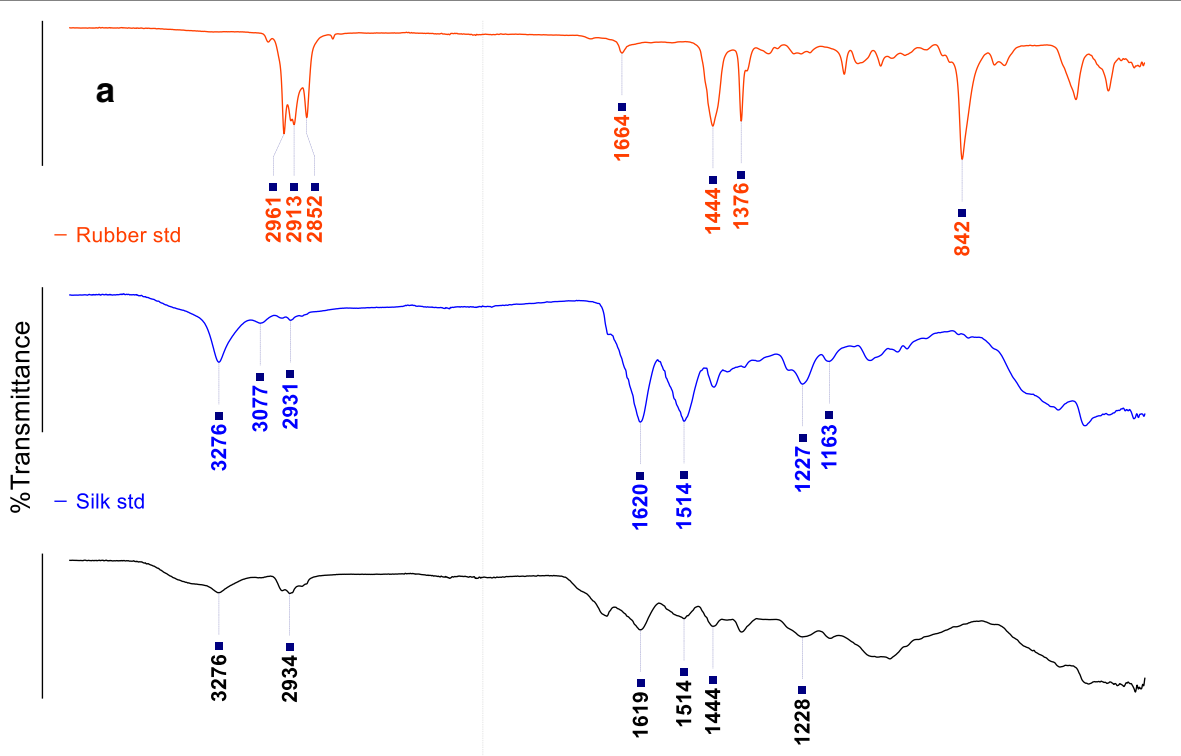

- Silk $+20 \%$ latex
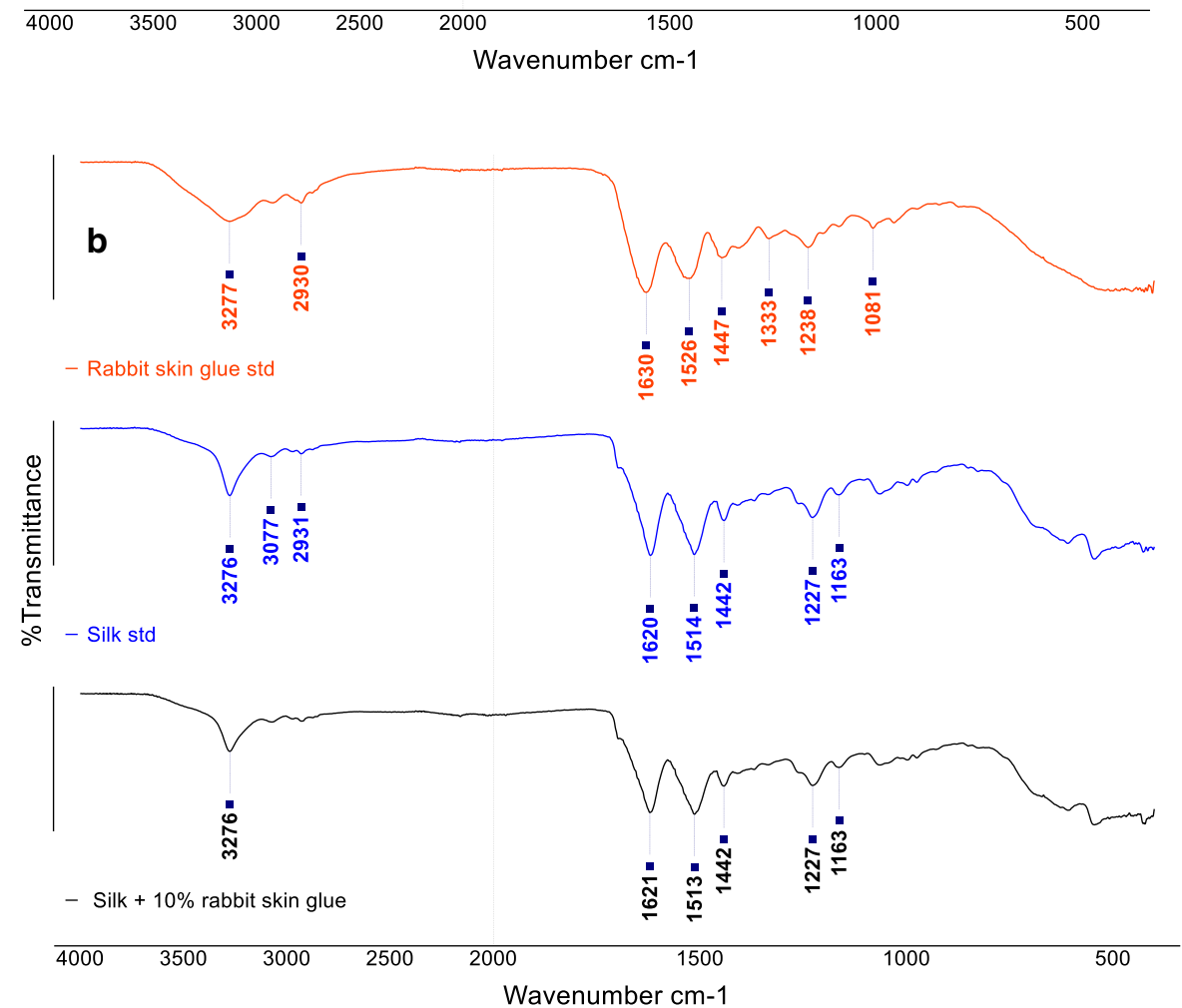

Fig. 14 FTIR-ATR spectra of reconstructions showing silk and latex and silk and rabbit skin glue compared to standards. a rubber and silk standards compared to silk with $20 \%$ latex, b rabbit skin glue and silk standards compared to silk with $10 \%$ rabbit skin glue

value of comparative techniques and is an important consideration, as fibre blends are not uncommon in banners.

The use of other non-invasive techniques will be important to be able to study a wide range of banners. Portable instrumentation, although not reported here, is obviously of great value in the study of painted banners as these will give a preliminary result which for example may identify a material or show surface cracking. However, portable FTIR (for example ATR and diffuse reflectance infrared Fourier transform spectroscopy-DRIFTS) 


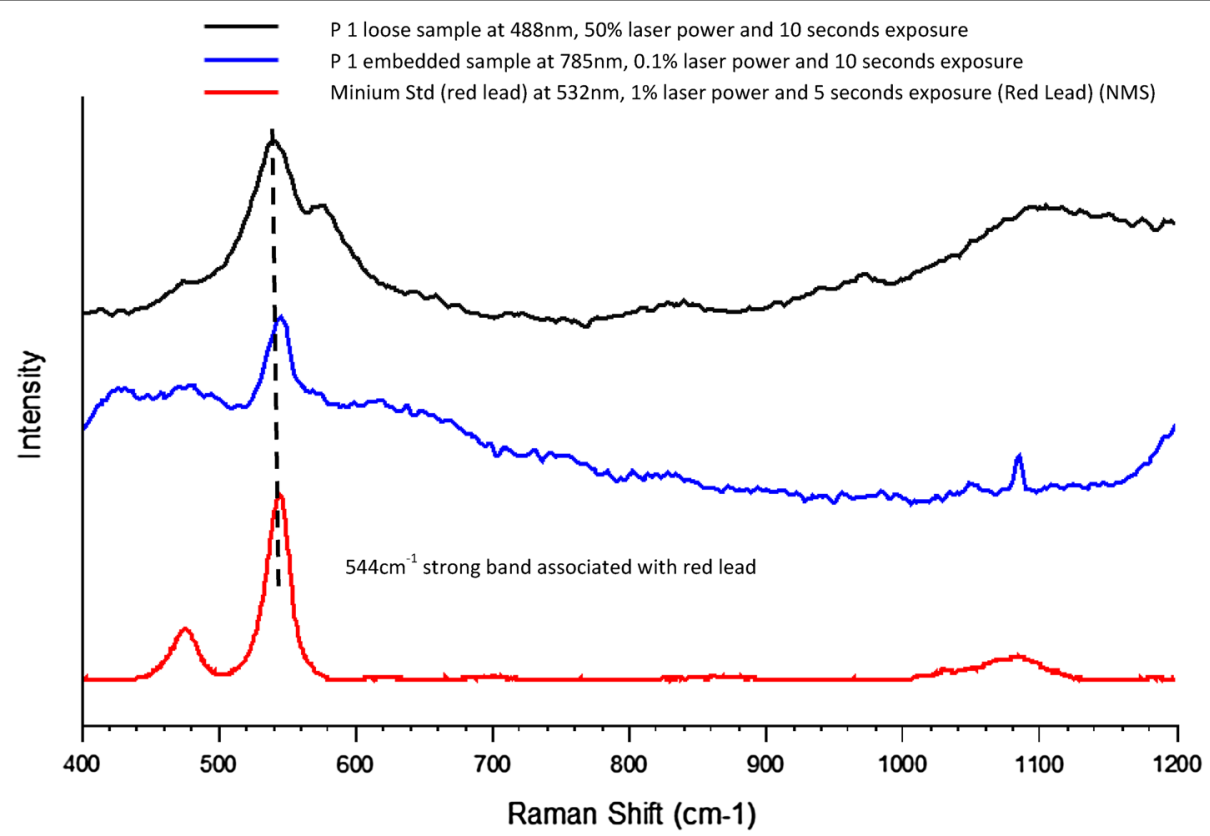

Fig. 15 Comparison of response of red lead at different Raman wavelengths

is not always the best option when dealing with uneven, partially degraded, multi-layered materials as the depth of penetration could lead to erroneous results due to the complexity of spectra produced. Portable Raman may not be suitable due to the levels of fluorescence caused by the organic materials. However their application using different wavelength detectors would need to be further investigated to determine its usefulness to fully understand painted textile materials and construction.

\section{Conclusions}

The focus of this investigation was to systematically identify the types of materials used by the banner maker which is crucial to not only understanding the materials used in its making but also to inform conservation. This included not only the textile and paint but also other components such as the coating on the wooden banner pole. Understanding the characteristics of all materials is considered important as some materials present may contribute to accelerated degradation of others.

The presence of the silk textile resulted in more complex experimental sample preparation and also problems resulting in interference signals from the textile during some instrumental analysis. These range from the problems encountered in FTIR with dominant signals in macro analysis which results in materials not being identified to the problems of protein stains where the presence of silk can obscure other proteins which are only present tiny quantities. The challenges of finding effective wavelengths for analysis of samples using Raman were clearly evident in this study.

Sampling provided very valuable information about the banner's construction and materials; this is a wellrecognised technique used in paintings analysis for conservation. The full cross section including the textile, albeit destructive, in particular yielded not only information about the banner's materials but also their interfaces which is crucial in understanding the composition and also to better understand its manufacture, and deterioration. This is essential to inform conservation. However taking full cross section samples would not be possible on many banners, unless there was significant damage through the painted areas, and where the paint does not extend to the edge of the object. Taking any sample from a painted banner is challenging due to the fact that the textile is not rigid and also that the paint layers are extremely thin (often around $10 \mu \mathrm{m}$ ). This means that it is difficult to achieve a cross-section of the paint layers alone as the thinness causes the paint to crumble. This is not necessarily the case with samples from paintings where the layers are usually much thicker.

Sampling from a variety of areas is important as materials and preparatory layers may vary within a banner as reported here and although portable instrumentation 
P1 embedded sample $785 \mathrm{~nm}$

P1 loose sample $785 \mathrm{~nm}$

P5 embedded sample $785 \mathrm{~nm}$

— P1 loose sample $325 \mathrm{~nm}$

Cerussite (lead white RRUFF database)
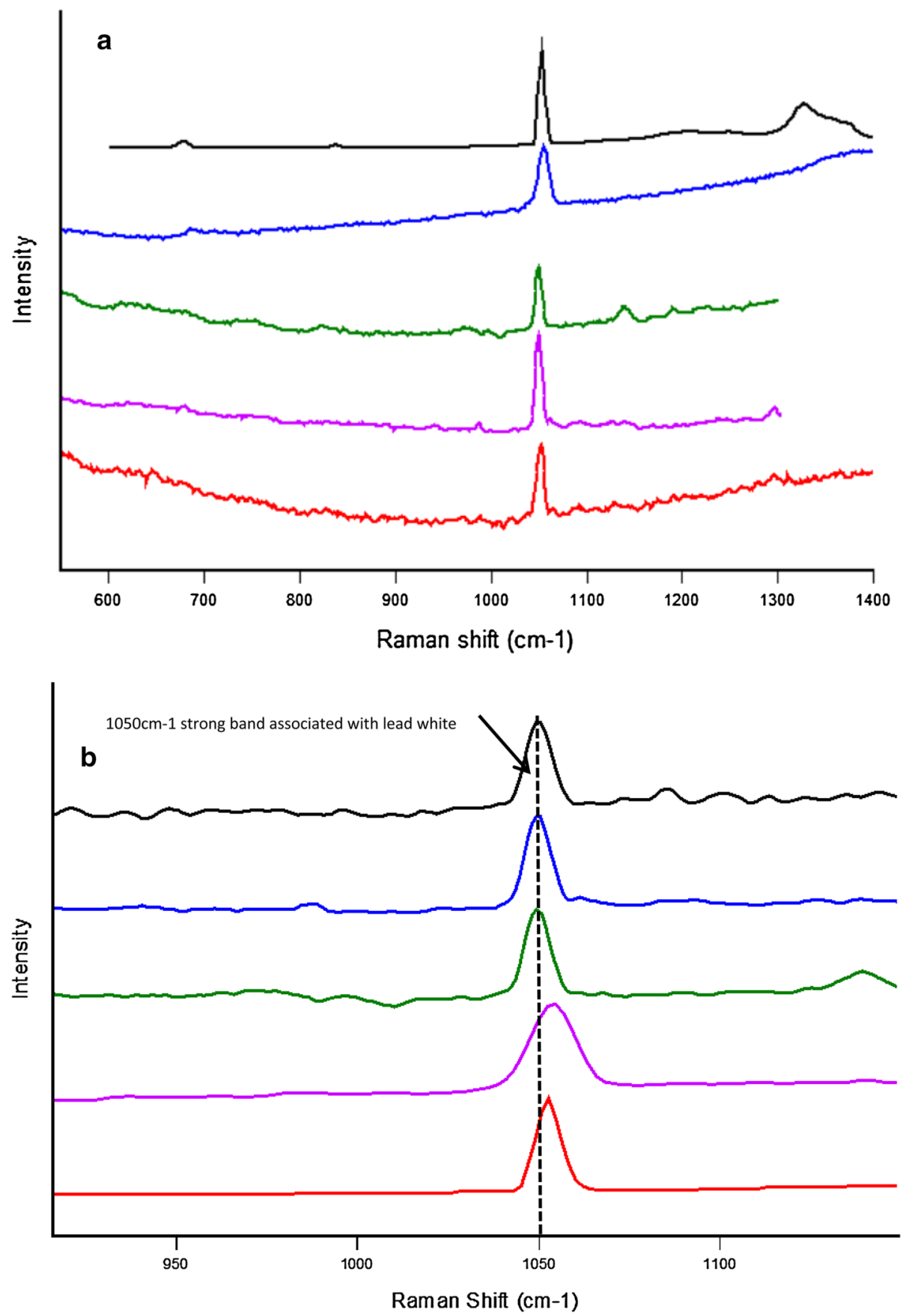

Fig. 16 Raman of lead white at different Raman wavelengths. aThe spectra as collected by the instrument.b The spectra with baseline smoothing and truncation of the wavenumber axis 

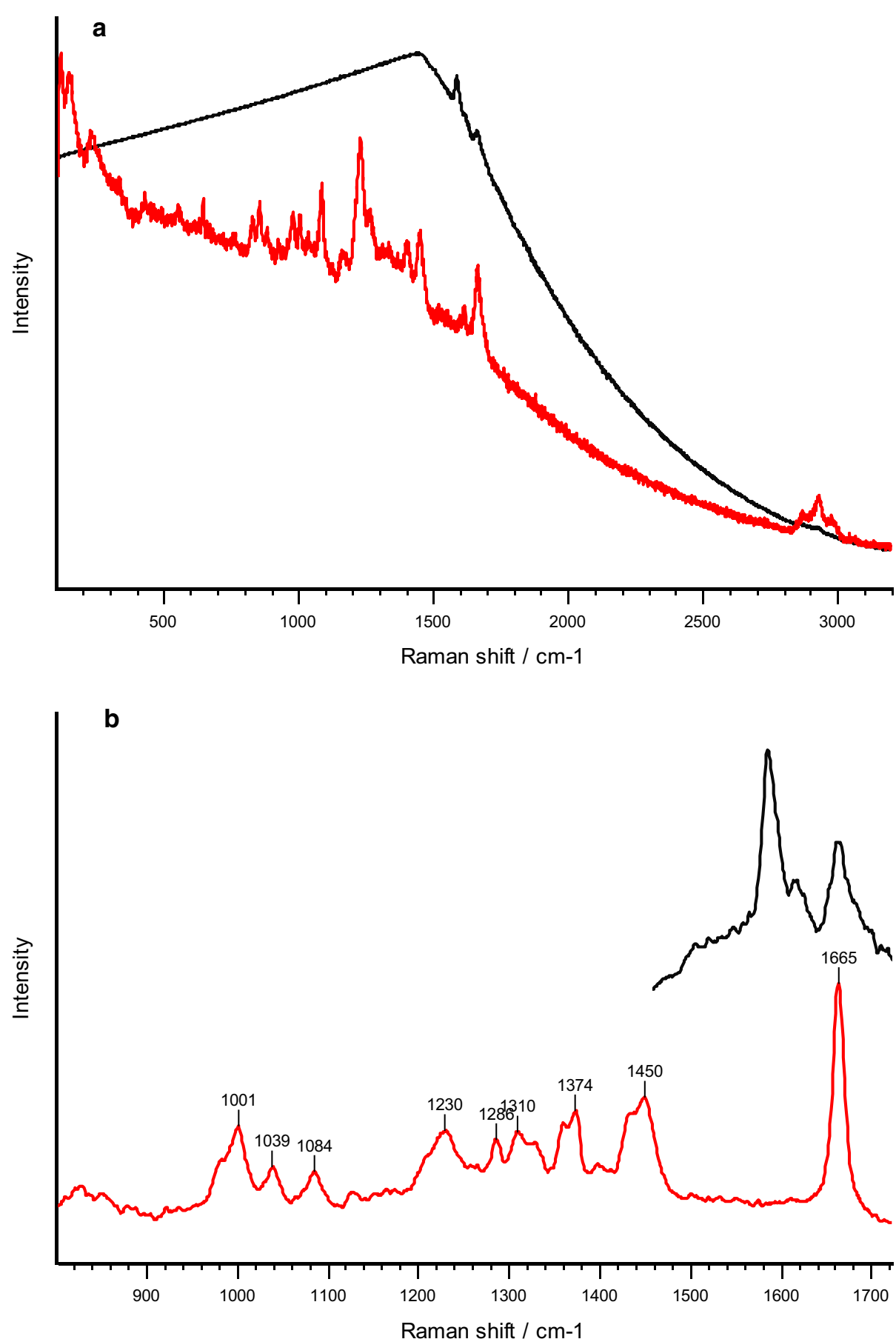

Fig. 17 a Embedded silk sample from the banner and a loose sample of new silk. No baseline correction, truncation or noise reduction carried out. b The same spectra after baseline correction, noise reduction and truncation using Renishaw Wire3.4 software

may be useful for in-depth understanding of the heterogeneous layered materials sample taking still remains crucial. While instrument manufacturers increasingly develop instruments that are 'easy to use', ultimately the value of analysis should be in rigorous interpretation and knowledge of the limitations of the instrumentation, something that can only be achieved by an understanding of the scientific principles behind the analysis. Conservation scientists perform a valuable role for conservators and curators who often only wish to identify or confirm 
Table 2 Material identified, position on banner and technique used

\begin{tabular}{lll}
\hline Material Identified & Sample positions & Analytical technique(s) \\
\hline Lead white & 1,3 & Raman; SEM-EDX; FTIR-ATR \\
Red lead & 1 & Raman \\
Aluminium & 2 & SEM-EDX \\
Silk & 4 & Light microscopy and \\
& FTIR-ATR \\
Calcium carbonate & 4 & FTIR-ATR \\
Metal soap & 4 & FTIR-ATR \\
Shellac resin & Pole & FTIR-ATR \\
Linseed oil & 4 & FTIR-ATR \\
Cotton & Fringe & Light microscopy and \\
& & FTIR-ATR \\
Viscose & Fringe & Light microscopy and \\
& & FTIR-ATR \\
\hline
\end{tabular}

the presence of a material, leading to the publication of many extremely enlightening and informative technical papers, but the results do not always speak for themselves. More in-depth examination and interpretation is required in order to fully understand interactions at interfaces and surfaces which will in turn help the conservator to understand and more effectively preserve these socially significant cultural objects.

\section{Authors' contributions}

MJS and KT prepared the samples, performed analyses, interpreted the results and wrote the paper. EH carried out the interpretation of the light microscopy samples. All authors read and approved the final manuscript.

\section{Acknowledgements}

Margaret Smith was funded by the Getty Foundation through the Research Network for Textile Conservation, Dress and Textile History and Technical Art History and AHRC Grant AH/M00886X/1. The authors wish to thank Frances Lennard for useful discussion during to preparation of this article. Also the authors which to thank the following people for their help in carrying out the analysis, Dr. Mark Richter, University of Glasgow; Dr. Lore Troalen, National Museum Scotland; Prof Anne Neville and Dr. Chun Wang, Institute of Functional Surfaces, University of Leeds and Mike Dixon and Dr. Thomas Schmidt, Hitachi Instruments.

\section{Competing interests}

The authors declare that they have no competing interests.

Received: 21 December 2015 Accepted: 26 June 2016

Published online: 08 August 2016

\section{References}

1. Mansfield N. The contribution of the National Banner Survey to debates on nineteenth-century popular politics. Vis Res. 2008;24(2):133-43.

2. Macdonald AM, Rogerson CE, Vaughan AS, Wyeth P. Raman microspectroscopy interrogating 19th- and 20th-century painted trades union banners. In: Janaway R, Wyeth P, editors. Scientific analysis of ancient and historic textiles: informing preservation, display and interpretation first annual conference. London: Archetype Publications Ltd; 2005. p. 222-9.
3. Takami M, Wyeth P. Studies on a Korean painted silk banner: identification of layer structure, binding medium and pigments. In: Whelan VJ, editor. Strengthening the bond, science \& textiles preprints, North American textile conservtion conference. New York: NATCC; 2002. p. 133-42.

4. Gorman J. Banner bright. Essex: Scorpion Publishing Ltd; 1986.

5. Labreuche P. India rubber painting grounds in Britain and France in the nineteenth century. Stud Conserv. 2011:56:14-30.

6. Lennard F, Lochhead V. United we stand! The conservation of trade union banners. In: Vuori J, editor. Tales in textiles, the conservation of flags and other symbolic textiles preprints of the North American textile conservation conference. Albany: NATCC; 2003. p. 111-8.

7. Rogerson CE, Lennard FJ. Billowing silk and bendable binders: is flexibility the key to understanding banner behaviour? In: Janaway R, Wyeth $P_{\text {, }}$ editors. Scientific analysis of ancient and historic textiles: informing preservation, display and interpretation. London: Archetype Publications Ltd; 2005. p. 12-8.

8. Schäfer S. A luminescent metal chelate stain and its application protocol for the identification of proteinaceous binding media within paint cross sections. In: Emmerling E, Kühlenthal M, Richter DM, editors. Coloured Glazes on Metal Leaf from the Baroque and Rococo. Siegl Anton: Munich; 2013. p. 7.

9. Kuckova S, Sandu ICA, Crhova M, Hynek R, Fogas I, Schafer S. Protein identification and localization using mass spectrometry and staining tests in cross-sections of polychrome samples. J Cultural Herit. 2013;14:31-7.

10. Giannuzzi LA, Stevie FA. A review of focused ion beam milling techniques for TEM specimen preparation. Micron. 1999;30:197-204.

11. Boon JJ, Asahina S. Surface preparation of cross sections from traditional and modern paint using the Argon ion milling polishing CP system. Microsc Microanal. 2006:12:1322-3.

12. Prati S, Rosi F, Sciutto G, Mazzeo R, Magrini D, Sotiropoulou S, Van Bos M. Evaluation of the effect of six different paint cross section preparation methods on the performances of Fourier Transformed Infrared microscopy in attenuated total reflection mode. Microchem J. 2012;103:79-89.

13. Prati S, Sciutto G, Catelli E, Ashashina A, Mazzeo R. Development of innovative embedding procedures for the analyses of paint cross sections in ATR FITR microscopy. Anal Bioanal Chem. 2013;405:895-905.

14. Zhang XM, Wyeth P. Using FTIR spectroscopy to detect sericin on historic silk. Sci China Chem. 2010;53:626-31.

15. Mazzeo R, Prati S, Quaranta M, Joseph E, Kendix E, Galeotti M. Attenuated total reflection micro FTIR characterisation of pigment-binder interaction in reconstructed paint films. Anal Bioanal Chem. 2008;392:65-76.

16. Weerd JVD, Loon AV, Boon JJ. FTIR Studies of the effects of pigments on the aging of oil. Stud Conserv. 2005;50:3-22.

17. Rode N. Towards a clearer understanding of the whitening effects on the surface of painted flags and banners. Southampton: The Textile Conservation Centre; 2003.

18. Stevens SC: Do you know where you are? Silk flank markers from the Civil War. In: Vuori J editor. Tales in the textile: the conservation of flags and other symbolic textiles, preprints of the NATCC, Albany, 2003: 87-98.

19. Salvadó N, Butí S, Nicholson J, Emerich H, Labrador A, Pradell T. Identification of reaction compounds in micrometric layers from gothic paintings using combined SR-XRD and SR-FTIR. Talanta. 2009;79:419-28.

20. Ferreira ESB, Boon JJ, Marone F., Stampanoni M: Study of the mechanism of formation of calcium soaps in an early 20th century easel painting with correlative 2D and 3D microscopy. In: Proceedings 16th Triennal Meeting of the ICOM Committee for Conservation. Lisbon: James and James: 2011:1-4.

21. Robinet L, Corbeil M-C. The characterization of metal soaps. Stud Conserv. 2003:48:23-40

22. Otero VD, Sanches C, Montagner M, Vilarigues L, Carlyle, Lopes JA, Melo MJ. Characterisation of metal carboxylates by Raman and infrared spectroscopy in works of art. J Raman Spectrosc. 2014:45:1197-206.

23. Learner T: The use of a diamond cell for the FTIR characterisation of paints and varnishes available to twentieth century artists. London: IRUG; 1995:7-20.

24. Prati S, Sciutto G, Catelli E, Ashashina A, Mazzeo R. Development of innovative embedding procedures for the analyses of paint cross sections in ATR FTIR microscopy. Anal and Bioanal Chem. 2013;405(2-3):895-905.

25. Prati S, Rosi F, Sciutto G, Mazzeo R, Magrini D, Sotiropoulou S, Van Bos M. Evaluation of the effect of six different paint cross section preparation methods on the performances of Fourier Transformed 
infrared microscopy in attenuated total reflection mode. Microchem J. 2012;103:79-89.

26. Zumbühl S: Derivatisation strategies for micro-FTIR and chemical imaging FTIR-FPA—fluorination reagents to discriminate spectral interferences in paint samples. In: 11th infrared and Raman users group conference. Boston; 2014.

27. Ajo D, Casellato U, Fiorin E, Vigato PA. Ciro Ferri's frescoes: a study of painting materials and technique by SEM-EDS microscopy, X-ray diffraction, micro FT-IR and photoluminescence spectroscopy. J Cult Herit. 2004;5:333-48.

28. Burrafato G, Calabrese M, Cosentino A, Gueli AM, Troja SO, Zuccarello A. ColoRaman project: Raman and fluorescence spectroscopy of oil, tempera and fresco paint pigments. J Raman Spectrosc. 2004;35:879-86.

29. Ali EMA, Edwards HGM, Hargreaves MD, Scowen IJ. In-situ detection of drugs-of-abuse on clothing using confocal Raman microscopy. Anal Chim Acta. 2008:615:63-72.
30. Lorenzetti G, Striova J, Zoppi A, Castellucci EM. Confocal Raman microscopy for in depth analysis in the field of cultural heritage. J Mol Struct. 2011;993(1-3):97-103.

31. Macdonald AM, Vaughan AS, Wyeth P. Application of confocal Raman spectroscopy to thin polymer layers on highly scattering substrates: a case study of synthetic adhesives on historic textiles. J Raman Spectrosc. 2005:36:185-91.

32. Analytical Methods Committee. Raman spectroscopy in cultural heritage: background paper. Anal Methods. 2015;7:4844-7.

33. Burnstock $A$, van den Berg KJ: Twentieth century oil paint. The interface between science and conservation and the challenges for modern oil paint research. In: Burnstock A, de Keijzer M, Krueger J, Learner T, de Tagle A, Heydenreich G editors. Issues in Contemporary Oil Paint. Switzerland: Springer; 2014

\section{Submit your manuscript to a SpringerOpen ${ }^{\circ}$ journal and benefit from:}

- Convenient online submission

- Rigorous peer review

- Immediate publication on acceptance

- Open access: articles freely available online

- High visibility within the field

- Retaining the copyright to your article 